\title{
FROM ADOPTION TO USE: THE PROCESS OF APPROPRIATING A MOBILE PHONE
}

\author{
Jennie Carroll $^{1}$ Steve Howard ${ }^{1}$ Jane Peck $^{2}$ John Murphy ${ }^{2}$ \\ ${ }^{1}$ Department of Information Systems \\ The University of Melbourne \\ jcarroll@staff.dis.unimelb.edu.au \\ ${ }^{2}$ Novell Pty Ltd \\ 574 St Kilda Road, Melbourne 3000
}

\begin{abstract}
Users appropriate a technology through a process of evaluation that results either in rejection or adoption, adaptation and integration of the technology into their everyday activities. Currently this process, and the influences on users' decisions within that process, is poorly understood. This paper reports a research project that examines young people's appropriation of mobile technologies. Thirty young Australians were supplied with a free WAP phone for a month and were tracked from their expectations, the initial encounter and the first month of use of a WAP phone. We found that the influences on their adoption of the phones were quite different to those on ongoing use and so the influences on adoption do not predict long-tern use. It is clear that studying adoption is only one step towards understanding technology acceptance and use and that rejection of a technology, even one that is supplied free of cost, is an ever-present option.
\end{abstract}

Keywords

Technology appropriation, technology adoption, diffusion of innovation, mobile technologies

\section{INTRODUCTION}

Technology innovation, adoption, acceptance and use have long been important topics for information systems (IS) research (Davis 1989). The life cycle of a technology-from designing and developing an innovation, communicating or diffusing information about it, deciding to adopt (selecting, purchasing or committing to use it) and then achieving persistent use-is poorly understood. Few studies differentiate between pre- and post-adoption (Karahanna, Straub and Chervany 1999); there has been little attention paid to the temporal dimensions of adoption and then only on a limited set of variables (for example, Davis, Bagozzi and Warshaw 1989). Our previous research (Carroll et al. 2001; 2002a), like most IS research, has examined perceptions of adoption behaviour after a technology has been adopted. This paper reports a research project that takes a processural approach to technology adoption and use and examines users' expectations prior to encountering a technology, the initial encounter and then the first month of use.

In this research project the focus is on young people. Young Australians are enthusiastic users of mobile technologies. About one half of young Australians aged 14 to 24 own a mobile phone and the number is rapidly increasing (Gooch 2002). Our research illustrates that they are also discriminating users of mobile technologies. Thirty young Australians were supplied with a state-of-the-art WAP phone. They had high expectations of WAP mobile phones: the functions they would provide, the time saved and their usefulness in their everyday lives. However, even though the phones were provided free of charge (for the device and usage), many of the young people did not integrate the phones into their everyday practices. Their verdict at the end of a month was 'No thanks'. We note that young people persist with technologies only when they add significant value to their lives. Further, the gap between their expectations prior to adoption and their evaluation after one month's experience indicates that merely studying the decision to adopt a technology is insufficient, as it is followed by a whole process of deeper evaluation through use that may, or may not, result in persistent use.

We have used research methods that are appropriate for the different experiences in this process to develop a rich view of young people's adoption and use of mobile technologies. The findings extend our existing work on young people's appropriation of mobile technologies and so contribute to IS theory. The findings indicate that the influences on adoption are quite different to those on persistent use and so the influences on adoption do not predict persistent use. Such a view contradicts the assumptions of much of the technology acceptance literature (see Davis 1989). The implications of these findings are significant for IS practice. Developers, marketers, trainers and managers should note that it is not sufficient just to adopt a technology, rather it is important to be mindful of the influences that affect persistent use when designing and marketing technology innovations and training and managing staff throughout the appropriation process.

After discussing the conceptual background of the research, the research approach is outlined, the research findings are presented and their implications are discussed. The paper concludes by presenting some of the shortcomings of the research that indicate areas for future work. 


\section{BACKGROUND}

This paper reports on the second stage of a collaborative research project with Novell Pty. Ltd called 'Customers of the Future'. It is a three stage project to investigate young people's perceptions and use of mobile technologies as the basis for technological innovation. Stage 1 (Carroll et al 2001; 2002a) provided a benchmark of young people's use of mobile technologies. It was also the basis for inducing a model of technology appropriation which we have defined as "the way that users evaluate and adopt, adapt and integrate a technology into their everyday practices" (Carroll et al. 2002b).

The model of technology appropriation was built through studying individual young people and their use of mobile phones - a technology that they had already appropriated (access to a mobile phone was a condition of participation in the study, see Carroll et al. 2002a). In Stage 2, discussed in this paper, we test the model by tracking young people from their initial encounter with an Internet-enabled mobile phone through their first month of use.

\section{The Model of Technology Appropriation}

The model of technology appropriation (Carroll et al. 2002b), shown in Figure 1, describes the transformation of a technology as it is envisaged by its designer (technology-as-designed) into technology as it is currently used (technology-in-use). The nature of this transformation is called the process of appropriation.

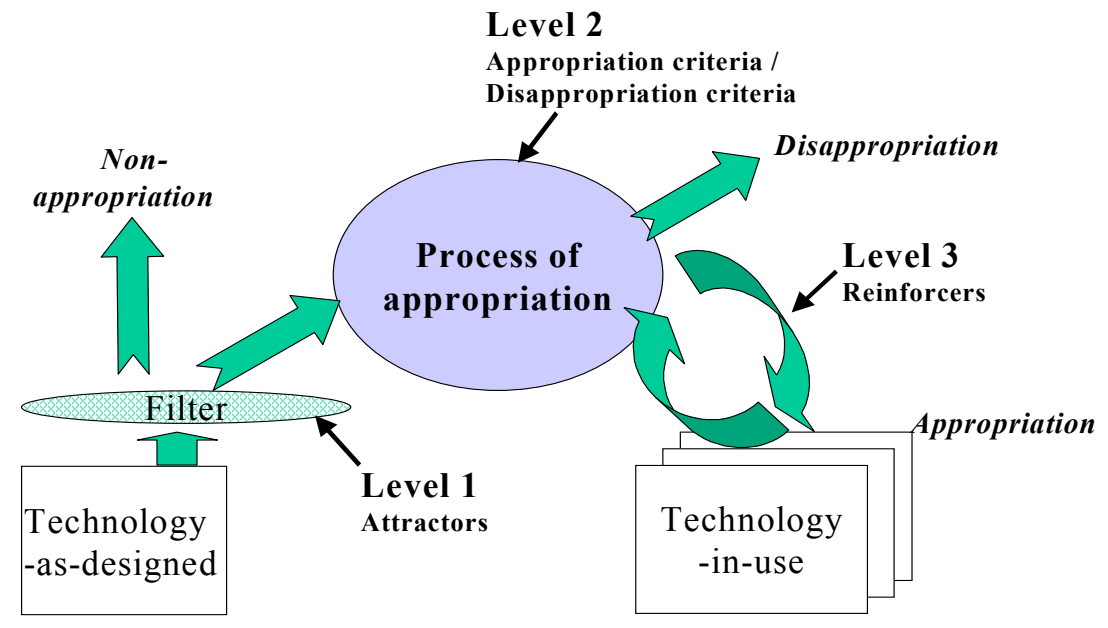

Figure 1: The model of technology appropriation (from Carroll et al. 2002b)

We suggest that users evaluate a technology at three levels, reflecting different degrees of familiarity with the technology at different times in the appropriation process (Carroll et al 2002):

- Level 1 relates to users' first encounter with a new technology, such as in a shop or a training session. At this level, initial judgements are made without any prolonged use of the technology. The outcomes of this filtering are either non-appropriation, where users are uninterested in the technology, or otherwise the decision to adopt (Davis 1989; Rogers 1995) initiates the process of appropriation.

- Level 2 reflects a deeper evaluation through use. If users are attracted by a technology, they will explore it in depth through the process of appropriation. There are two possible outcomes. Appropriation occurs where the users take possession of its capabilities in order to satisfy their needs. Disappropriation occurs when, at some stage during the appropriation process, users choose not to persist with the technology.

- Level 3 captures the longer-term use of a technology. The technology is appropriated and integrated into users' everyday practices. This is not a one-off activity but rather is subject to ongoing reinforcement; changes in users' evaluation of the technology may lead to disappropriation.

This suggests that technology appropriation involves evaluation by users as they encounter (Level 1), adopt and adapt (Level 2) then integrate (Level 3) a technology into their everyday practices. Further, in Stage 1 of the research we observed that different influences operate at the three levels. At Level 1 - the initial filtering-attractors encourage the users to further explore the technology and a lack of attractors may dissuade users from deeper evaluation, resulting in non-appropriation of the technology. At Level 2-during the process of appropriation_criteria encourage continuing evaluation or rejection of the technology. These 
criteria influence the decision to either appropriate or disappropriate the technology. Finally, a set of reinforcers act to maintain use.

We have tailored the model to reflect our focus on young people and mobile technologies. During Stage 1 we identified attractors, appropriation and disappropriation criteria, and reinforcers that influence young people's appropriation of mobile technologies (Carroll et al. 2002a).

\section{RESEARCH APPROACH}

The model of technology appropriation was derived from a study of young people's use of mobile phones; it was based on a biased cohort as all participants owned or had access to a mobile phone and so by definition the filtering process at Level 1 had been resolved in favour of deeper evaluation. In Stage 2 we provide the participants with a new technology and so are able to study their initial encounters with a new technology (Level 1) as well as medium term evaluation (Level 2). Due to the limited duration of Stage 2, Level 3 influences that reinforce use were not observed.

In Stage 2 we are seeking to confirm, disconfirm or extend the model of technology appropriation and the influences it describes on young people's appropriation of mobile technologies. The characteristics of the new technology were selected to enable testing of the model. We studied the young people's responses to:

- The user interface. The Internet-enabled phone was new in the Australian mobile phone market and had an unfamiliar user interface. We were interested in examining the effect of a different interface on young people's evaluation of the phones.

- The network. The phones used a new network that was only partly functional at the time of the project, in that users were unable to send text messages outside the supplier's network. We were interested in investigating the effects of this limitation on the young people's SMS (Short Messaging Service) patterns, in particular whether - in the absence of cost concerns - voice calls and text messaging were interchangeable.

- WAP phones. The mobile phones used Wireless Application Protocol (WAP) to access the Internet. WAP is a standard for mobile Internet access that enables wireless devices such as mobile phones and PDAs to access special Web pages.

- Internet access. The mobile phones were configured so that the Internet was accessible via a security connection; this could be avoided if the young people reconfigured the hand set to overcome the inconvenience. We were interested in the way that the young people dealt with this limitation and whether they attempted to adapt the phones to make it easier to access the Internet.

The research was undertaken between May and July 2001 and involved 30 young people (21 had participated in Stage 1) from Melbourne and Sydney. The research participants were recruited by professional recruiting companies on the basis of access to a mobile phone and the Internet as well as possession of their own email address. All were aged between 16 and 22 and were either students (secondary or tertiary) or workers.

We used a similar empirical process to that for Stage 1 (Carroll et al 2002a). Questionnaires and focus groups collected data about young people's expectations of Internet-enabled phones. The participants' initial encounter with the new technology was studied using a co-discovery process (O'Malley, Draper and Riley 1984). This involved participants working in pairs exploring the Internet-enabled phone and articulating their actions and perceptions to a researcher; the sessions were audio-recorded. These research methods were directed to examining the influences at Level 1 of the model of technology appropriation: those that bear on the decision to adopt, also called 'pre-adoption' (Karahanna, Straub and Chervany 1999).

During the month of use, six participants in Melbourne were observed in their everyday activities in leisure, social and educational contexts at different times during the week, the weekend and holidays. Participants also completed an online diary for two days a week for the month, providing a record of their use of the phones. At the end of the month, a second questionnaire and focus group self-reported participants' perceptions and use of the WAP phones. Finally, their itemised phone bills (separated into voice calls, SMS messages, Internet use, call diverts and voice mail) for the month were accessed and analysed. These research methods related to the deeper evaluation of a technology through use described by Level 2 of the model of technology appropriation, also called 'post-adoption' (Karahanna, Straub and Chervany 1999). As we were studying a process of appropriation, longitudinal data - rather than snapshots of use-were collected over one month.

The data were analysed using coding (Miles and Huberman 1994); the concepts in the model of technology appropriation were used as the initial codes to guide the initial analysis, along with 'any other' codes to incorporate new themes that were noted in the data (Carroll and Swatman 2000). The resulting codes were refined through re-reading the qualitative data, comparing and contrasting this with the quantitative data and finally examining the temporal relationships between the resulting categories.

Together, these research methods provide a rich and detailed picture of the young people's initial expectations of Internet-enabled phones, their usage patterns over their first month of use and their evaluations of the phones at the end of a month of use. 


\section{FINDINGS}

\section{Expectations}

Most (27) participants had heard of a phone that connects to Internet and some (11) knew it as a WAP phone but had not seen such a phone. Only four of the participants recognised that WAP sites would look different to regular web sites accessed from a personal computer (PC). Thus there was little awareness that viewing the Internet through a WAP phone would provide access only to a very small number of Web sites (a limited number of Web sites are available in WAP form) and only to a sub-set of the content of these Web sites.

Many of the young people expected that the main uses of an Internet-enabled phone would be reading email and accessing information sites. Others had more limited expectations; one female participant said "It's not like you can check your email or anything, as far as I know." When asked about the likely effects on their lives, most participants were uncertain and wanted to see what an Internet-enabled phone could do first.

\section{The Model of Technology Appropriation: Level 1}

The influences noted on young people's initial encounters with a technology in Stage 1 were fashion/style, cost, convenience, usefulness, adaptability, familiarity and 'our stuff' (Carroll et al 2002b). At the end of Stage 1, one group of young people nominated fashion/style and cost as the two main drivers for adoption of a particular mobile phone. In Stage 2:

- Fashion/style was evaluated on the size, weight and appearance of the handset: "I really thought that this would be heaps bigger and heavier... It's actually really compact", "Looks nice", "It's really cool" and "it's alright but nothing special." One participant described how she evaluates a mobile phone by its looks rather than by the features it offers: "It's more... how I like the phone to look, rather than it has to have the Internet on it."

- The participants thought that the Cost of both WAP handsets and usage would be greater than normal mobile phones. Even the idea of sending email was evaluated according to cost; asked whether she would send an email, one girl replied "It depends on... what the charge was, say per character or just the message."

- Expected Usefulness is the degree to which users expect that using a technology will provide them with benefits (adapted from Davis 1989:320); a synonym for usefulness is convenience. The young people expected that the Internet-enabled mobile phone would be used for email (18), gathering information such as movie times, news, weather and banking (12) and accessing the internet (11). They suggested that the ability to check email anytime anyplace, for example while waiting for a bus or an appointment, would be good. These expectations were supported by participants' comments during the co-discovery: "This is fantastic, I've just got into the Ski Report bit... It tells you everything.. Um..lifts operating. This is fantastic. This tells you absolutely everything you need to know. "Being able to connect to the Internet anywhere would save time and make contacting others easier: "You can find out information when you need it" and "It would make me a lot more mobile."

- Adaptability: in Stage 1 we noted the importance placed by young people on the ability to personalise a mobile phone, such as change ringtones or covers (change the colour or pattern of the face plate). Most participants adapted the phone during co-discovery by resetting the ring tones, changing the volume or personalising the greeting banner. One of the first actions of many of the young people during the co-discovery was to customise the greeting banner: "I've just changed my banner. It says 'Sam rocks'. That's cool." A sixteen year old girl listened to the ring tone "I'm not happy with it - I think I'll change it [different ring tones are heard]."

- Familiarity: The participants were familiar with certain interfaces and functions provided on mobile phones, especially Nokia phones which are the most popular brand amongst this age group (owned by $70 \%$ of the participants). The different interface provided them with some problems; in the codiscovery a pair of young boys were trying to turn on the phone: "It's no Nokia. Oh god, I hate doing this...It's got all these tools but I don't know how to turn the damn thing on." Others said: "It's different. I'm so used to the Nokias" and "it is a bit different to my phone... so just getting used to it." Some participants spent the early time in the co-discovery flipping through the manual while their partner explored the phone, but this was generally perfunctory: "The thing about using phones...It has all this stuff about 'Get things started' and things like that but whenever we get a phone we skip all that sort of stuff and we go into the fun stuff like how to use the email account first". Lack of familiarity with the interface and Internet access via a mobile phone led a number of participants to consider using the manual: "Maybe we should actually read the book... We might actually be able to work it out." 
- 'Our stuff': In Stage 1, one participant described mobile phones as 'our stuff': young people's technology with which they are comfortable. In Stage 2, the participants readily identified the phone as suitable for their age group: "It's really cool. It's like a new toy" and "They're ace." Features such as Voice Memo triggered enthusiastic responses: "oh this is so exciting... I've recorded my voice." Once they had discovered how to turn on the phone, most of the young people appeared very much at ease with basic features of the technology and quickly adapted it to their needs, for example by increasing the volume or selecting an appealing ring tone. However, one male participant struggling with interface said: "I feel like an old man with this, seriously.. you know how some old people have no idea..." It appears that 'our stuff' is a composite concept: our stuff is fashionable and fun, can be adapted to young people's needs and desires, as well as familiar or easily mastered.

Two additional Level 1 influences were noted in Stage 2:

- Ease of use: In Stage 1, usability was noted as an influence in Level 2 (disappropriation criteria). However, in Stage 2 we observed that ease of use was an important Level 1 influence. A pair of school-aged boys was asked for their initial impression of the phone: "I like it... Lots of nifty tools.." but when they were asked whether they knew enough to make a purchasing decision, the response was "Not really, the functions are good but it also has to be user friendly. It can have all the functions in the world.... [but] it took us ages to turn this thing on." The handset had a central black button to control interaction; it toggled between five options: right, left, up, down and centre (Enter). During the co-discovery, most participants found this hard to use: "I don't like this button." "It's so annoying. You push the button and you don't know if it's doing anything.", "This black thing is so sensitive, hard to control" and "I so do not like this button." Problems with the black button led one participant to state: "This is not a useful tool." The ease of use of the handset was enhanced by the large screen and the easy-to-read text: "Huge screens - very nice" "The main thing is the bigger screen on it, it makes the phone bigger but it is more convenient." However, one practical issue was noted: "No one would want to sit in front of a telephone reading pages of information."

- Features: The features offered by a mobile technology are an important influence on whether it is adopted: "When you first get a phone you want to look at all the features, look at them, look at the games and stuff..." The phone offered a number of new features: "This is great new stuff, emails..." "It's got a stop watch, calculator...not baaad...", "I love the calendars, love that.." and the Internet search: "Wow! It's unbelievable!" . Other features including an Alarm Clock, Tip Calculator and Voice Memo; these were described as "cool" and "exciting". Participants liked the Help on the phone (at bottom of screen). When asked how it differed from her normal phone, one female participant responded: "More options... It's got a lot more things than I thought. It's just a little smart cell."

The Stage 2 analysis of the data on Level 1 confirmed and extended our findings from Stage 1 (see Carroll et al. 2001; 2002a). An outcome of Stage 2 was refined definitions of the influences at Level 1 and the relationships between them. Cost is composed of the 'up front' purchase cost and the expected usage costs. Expected usefulness reflects the benefits that are expected from use of a technology and is an outcome of the application of the technology's features in context (geographical, social, temporal). Features are a combination of the physical functions that are offered by the phone and its associated services. 'Our stuff' reflects the extent to which the young people associate the technology with their age group and is fashionable and fun, can be adapted to young people's needs and desires, as well as familiar or easily mastered. Fashion/style reflects the size, weight and appearance of the mobile phone. Adaptability is the extent to which users can personalise a phone. Familiarity is the degree to which users have knowledge of the technology, its interface and the services it offers. Ease of use is the degree of effort required to use a technology; concepts such as 'user friendly' and 'usable' are reflections of ease of use.

\section{Non-appropriation or adoption?}

The Level 1 influences had mixed effects on the young people's initial evaluation of the WAP phone. Expectations of usefulness and adaptability were positive, there were diverse responses to the fashion/style and the familiarity of the handset while it was generally accepted as 'our stuff' (it was a mobile phone, albeit with some additional and unfamiliar features). Initial negative expectations of Internet-enabled phones related to cost; by removing cost as a variable, we hoped to encourage the participants to explore the technology freely. There were differing views of the ease of use of the phones: negative views of the unfamiliar interface and the black button and positive views of the large screen and text. Several participants also commented on possible negative social effects of the phones: "People are addicted to mobile phones and the Internet as it is; to put the two together you would probably never stop playing with it." and "It would make some people more anti-social, spending a lot of time walking around using the internet on their phone." 
Overall, the participants' comments at the end of the co-discovery were positive: "I'm going to have a lot of fun with this", "I love it. I want to have one but it's probably too expensive." "I think it's great - I am hooked" and "This is fantastic... I've got a very bad feeling I could spend hours on this." One male studying computing at University asked: "At the end of the month do these go up for sale to us? Cos I was seriously considering buying one... They're pretty cool." None of the participants discussed not using the phone or withdrawing from the research.

These positive expectations at the time of adoption did not, however, predict ongoing use. In the next section we examine the young people's experiences when using the WAP phones over the next month.

\section{The Model of Technology Appropriation: Level 2}

Level 2 of the model of technology appropriation reflects users' deeper evaluation of a technology through use. An unexpected finding was that the influence of a number of attractors noted at Level 1 persisted beyond the initial encounter and into the process of appropriation. As the young people used the WAP phones, the value given to some of the attractors changed.

- The initial evaluation of their adaptability was positive but experience using the phones showed that only very limited personalisation was possible. At the second focus group there were negative comments about the inability to download ring tones from the Internet and to buy covers for the phone to personalise its appearance (as is done with Nokia phones).

- Many of the young people only discovered a sub-set of the features offered by the phones (this was exacerbated by its unfamiliar interface and their reluctance to use the manual). After a discussion in the second focus group of the different features, a female university student said (soto voce) 'I didn't realise that all of this was possible." The value of offering a large number of features is questionable: young people want useful features. A young female said that she just wants a basic phone with different rings (different tones for different callers) and games "for when I get bored." One male university student said that that it was "not the stuff to attract 18 to 19 year olds" while another stated that there were "plenty of options available but I don't think they've set it out right"; it is the combination of features, their usefulness and their ease of use that is attractive.

\section{Level 2 Appropriation criteria}

The Level 2 influences on young people's appropriation of mobile phones noted in Stage 1 in the research were social management, lifestyle organiser, leisure, safety and security, critical mass and contact (Carroll et al 2002a). Interesting outcomes related to social management/contact and leisure were noted in Stage 2 as well as an extra criterion, usefulness. The addition of usefulness is supported by Davis (1989) who argues that perceived usefulness and ease of use play a central role in predicting and explaining user behaviour. Further, he suggests that ease of use may be an antecedent of usefulness because users adopt an application "primarily because of the functions it performs for them and secondarily for how easy or hard it is to get the system to perform those functions." (Davis 1989:333).

- Social management/ contact: The ability to use mobile technologies any time and any place, asynchronous and low-cost communication through SMS and critical mass amongst a social group all help young people to manage their social lives and maintain contact with the diverse people in their lives. We were interested in whether voice calls and SMS are interchangeable for young people. At the time of the trial, text messaging was limited to within the network (the network is now fully implemented and this limitation no longer operates). At the first focus group, participants suggested that they would ring friends using other networks to compensate for the limited SMS service. However, during the month of use many participants paid to use their own mobile phones for SMS while retaining the free WAP phone for voice calls. Young people are extremely sensitive to cost and their willingness to pay for the capability to SMS shows its importance in their lives. We observed subtle nuances of friendship between friends that are SMSed and those that are called. Asked why her SMS messages were not signed, a school-aged female responded that she uses SMS between close friends so the identity of the sender is obvious. If she is SMSing not-so-close friends, she starts off with "Hey its Sam" or, more usually, she will ring them. If it is someone she rarely speaks to, then she would email them. Also, SMS is more appropriate in some situations: "I couldn't do messages when I am in a lecture, you can't call... normally you can sit there and say 'I'll be out in half an hour' but with this you would have to leave and make a call." It was clear that voice calls and SMS are not interchangeable and that SMS is a particularly important technology to the young people. 
- Leisure: Several unexpected findings about the use of the phone for leisure activities were observed. The first relates to the design of the handset, where interaction occurs through a multi-functional Black Button. Leisure use was inhibited in certain situations: "The black button is quite loud... when you are in a classroom the teacher can hear when you are playing [games] under the desk in class." The second relates to the use of mobile phones for 'pranking'. Pranking often requires caller anonymity, which was not possible with this handset. This was described as "pretty annoying" and many of the school-aged participants complained about this: "I wanted to prank someone, but you can't take your number off." Young people prank each other so that the recipient bears the cost of the phone call: "I've got a missed call, so I will ring back". Another aspect of pranking is to bully others - to send unpleasant and anonymous messages. A final aspect of pranking discovered by some participants involved use of the Speaker Phone feature. A participant rang an acquaintance and had an intimate conversation about relationships; the receiver was unaware that the conversation was being broadcast on a Speaker Phone to another three young people: "The Speaker Phone was good. It was good when you prank people with it." This use of the Speaker Phone indicates how the young people adapted a feature of the phone to their leisure practices in a way that was unexpected and presumably outside the designers' intentions.

- Usefulness: The features of the WAP phones, especially email and the Internet, were not as useful as the young people had anticipated: "it didn't help me with many things", "it was not for my lifestyle... I don't find it necessary" while a third participant described it as "just like a novelty." Email use was limited. Many couldn't collect email as Hotmail (their favoured email provider) did not have a WAP site. Those who could access their email mainly read rather than sent email due to difficulties of entering email addresses and messages with phone keyboard. Their experience of email as hard to use and unreliable to connect meant that "Email is not worth it."

Participants had high expectations of the Internet but were frustrated when they realised the difference between usual Internet sites and WAP sites: "I thought 'Great', an Internet phone. I can search the Web but I didn't realise the Web and WAP are different and you need a Web site to have a WAP site on it to be able to go onto it." In the end, "I just thought it was easier to use a computer" because a computer is stable, easier to use and a whole page can be seen at once. Several participants described Internet access from a phone as a novelty: "It's a toy." Once the initial novelty wore off, they made little use of the Internet as it did not provide value: "it promises a lot but when you get into the Web, there is not much there." There are no images so many sites were not worth visiting. The billing data shows that over the month, use of the Internet dropped for almost all participants.

The inability to SMS to other networks was "a big annoyance." This was one reason that participants disappropriated the technology: "I have found that I am using my phone less, most of all because of the factor that most of my friends are on different networks which makes SMS use very hard."

We described usefulness above as an outcome of the application of the technology's features in context. The WAP phone was used in a wider range of contexts than expected: not just when out with friends or in transit but also in their bedrooms: "when I was in bed at night and I couldn't be bothered going downstairs, if I wanted to check an email I would ... or if someone else was using the computer". Even if a PC was available, some found that information such as movies and weather was easily found using the WAP phone. One participant described the phone' usefulness for multitasking: "my brother was sitting at the computer but used my phone to check the surf report... because he was playing a game..."

\section{Level 2 Disappropriation criteria}

Criteria noted in Stage 1 that influence young people's decision to disappropriate a technology were hidden cost, health, reception, ease of learning and usability (Carroll et al 2002b). Two notable findings observed in Stage 2 relate to ease of learning and ease of use (usability). While these were observed as two separate influences on the young people, previous research has indicated that ease of learning is a component of ease of use (Davis 1989).

- Ease of learning: The young people played with the phones rather than read a manual: "I found things by accident... I wasn't trying... you just play around and if you find something, you find something and if you don't, you don't." As a result, different participants discovered different things about the phones. This confirms our assumption that technology in use is heterogeneous, as illustrated by the multiple technologies-in-use in the model of technology appropriation in Figure 1.

Few participants admitted to using the manual except to try to resolve specific problems (for example, a female changed the language of her phone to Spanish and was unable to read the menu in order to change it back to English). Some participants found it hard to master the phone and many 
noted that the period of exploration and play lasted only for a short period: they "didn't have the time to fiddle after the first few days." This was compounded by the lack of reward for effort: as the phone was "not serving my interests that much" there was little encouragement to continue to learn to use the phone. This limited opportunity for learning (see Tyre and Orlikowski 1994) and low use of manuals has implications for the introduction of radical new interfaces or features. If innovations are not quick and easy to learn, they may remain undiscovered by young people. In absence of effective alternatives to manuals, incremental additions to familiar interfaces may be preferred.

- Ease of use: The large screen and easy-to-read text was appreciated: "I actually didn't think the screen was too big, it needs to be wide for the Internet.... Even with a big screen it is still very difficult to read emails and stuff on the screen." There were several usability problems: the black button, lack of reverse scroll (so that users could not scroll up to the top and beyond to the bottom) and slow access to the Internet. There were complaints about the number of steps needed to access Contacts (quicker access is available but was not discovered by the participants) and aggregating all recent calls in the one list (they were differentiated by symbols but many of the users were not aware of this). Data entry was a problem: "the phone does not have a keyboard which can make trying to gain access to websites and typing emails and other long information storing/data storing transfers slow and frustrating compared to using a PC or laptop." In summary, one male university student said that his friends thought the phone looked "unreal", but he thinks they would change their minds about the phone after using it; the difficulties of using it outweigh its appearance. A female participant described how 'the idea of an Internet phone has 'Wow' value but when you realise how difficult it is to use, you say '*!@*^ that'."

\section{Appropriation or disappropriation?}

At the end of the month, many of the participants had appropriated aspects of the phones; for example, the Internet "was pretty good, it did meet my expectations" and "Voice Activation ... was good". A few participants disappropriated the phone completely: "I just gave up" and "I just didn't go near it I hated it so much". Overall, the high initial expectations were not matched by their experiences: "email is too hard" "apart from the free calls I'm pretty happy to go back to my own phone" and "I just thought it was easier to use the computer." Billing data supports these comments and show a decrease in Internet access over the month.

\section{DISCUSSION}

$\mathrm{n}$ this research we have studied individual young people's very early encounters with a new technology: their expectations (via a questionnaire and focus group) and then their actions as they unpacked, switched on and examined a WAP phone (via a co-discovery session). At the end of the co-discovery-at the time of adopting the WAP phones - the young people were enthusiastic with positive expectations of the phones. Attractors such as expected usefulness, adaptability, fashion/style and familiarity were evident and the phones were generally accepted as 'our stuff'. Initial negative expectations of cost were neutralised by providing free phones and usage. Some aspects of ease of use were viewed negatively as were possible social effects of the Internet-enabled phones.

We tracked the first month of use when deeper evaluation and adaptation of the new technology is undertaken. At the end of the month, many participants' experiences of WAP phones did not meet their expectations. The outcome of the deeper evaluation was that, for many of the participants, aspects of the technology were disappropriated and a few disappropriated the phone completely.

These findings contribute to IS theory in two ways: they extend our existing work on young people's appropriation of mobile technologies and they indicate that focussing on the decision to adopt a technology is inadequate. They also contribute to IS practice. The contributions are discussed below.

\section{Technology appropriation}

We have defined appropriation as "the way that users evaluate and adopt, adapt and integrate a technology into their everyday practices" (Carroll et al. 2002b). This research has refined and extended the model of young people's appropriation of mobile technologies. We have revised the influences at Level 1 and clarified their definitions and interrelationships. The model, shown in Figure 1, presents three discrete levels. Our findings from Stage 2 of the research suggest that there is significant overlap between Levels 1 and 2. While the attractors at Level 1 relate to the users' initial expectations (of cost, usefulness, fashion/style, adaptability, familiarity, 'our stuff', features and ease of use), some of the attractors continue to have influence during the 
first few days or weeks of use. This suggests that appropriation involves a gradual drift through the levels rather than progression through clear-cut levels.

In addition, our earlier work involved mobile technologies that had already been successfully appropriated. We have extended this by studying young people's expectations and initial encounters with a new technology; the outcome is a understanding of the influences on their decision to adopt a new technology that is grounded in their actual practices rather than post hoc recollections.

The research has also described the way that technology is adapted as part of the appropriation process. Adaptation may take different forms: changing the physical configuration of the technology, changing the purposes for which existing features are used, and users changing their activities to accommodate the technology. Limited adaptation was observed in this research; this reflects the physical capabilities of the handset, the 'interpretive flexibility' (Bijker and Law 1992) of the technology and the short duration of the trial period. The handset could be configured to enable easier access to the Internet, to represent menus in text or icons and attributes such as ring tones and greeting banners could be altered within the alternatives provided. The technology was flexible in that some of its features could be shaped and re-interpreted to meet the young people's needs: use of the Speaker Phone for pranking illustrates a popular adaptation. Minimal adaptation of young people's practices was observed, possibly due to the limited time of the trial. One such adaptation was the use of multiple phones in order to meet conflicting needs (saving money through use of the free phone for voice calls and social management through use of their normal phones for SMS).

\section{Adoption and appropriation}

We have argued (Carroll et al 2002b) that different influences affect young people's decisions to adopt and to persist in using (appropriate) mobile technologies. Few IS studies differentiate between these decisions, also called pre-adoption and post-adoption (Karahanna, Straub and Chervanny 1999). The decision to adoptoften involving selection or purchase rather than implementation of a technology (Fichman 1999) - has received a great deal of attention (for example, Davis 1989; Rogers 1995). This study demonstrates that a focus on adoption is not sufficient. In order to predict and explain technology use (Davis 1989), we need to examine technology appropriation over time: users' expectations, the decision to adopt and actual use. By triangulating data methods and collecting data over time, we have developed a rich view of technology adoption and use. We have also clarified the changing influences that affect users' evaluations as they shift from expectations to experience.

The research has also demonstrated the importance of studying new technologies in context - what users actually do - rather than asking users what they think they will do. Initially the young people were not concerned about the limitations on SMS and they suggested that they would use free voice calls instead. Their intentions, however, were not carried out; SMS is an important part of their social lives (and an important gauge of closeness of friendship in some social groups) and the participants were willing to pay the price, both financially and with the inconvenience of using two mobile phones, to use SMS. Also, intentions must be modified in response to contextual issues: it is only when users are in certain contexts that limitations of a technology become evident (for example, SMS and voice calls are not interchangeable in a lecture theatre). Further, no matter how innovative or lateral thinking designers may be, they cannot imagine every use and situation of use for their designs; this is illustrated by complaints about a noisy button when playing games in a classroom.

\section{IS practice}

This research has implications for those involved with the development, adoption and use of technologies, such as designers, marketers, trainers and managers. The model of technology appropriation presents the influences on young people's evaluation, adoption and use of mobile technologies. Knowledge of the different influences that affect users' practices at different times in the technology lifecycle enables more effective targeting of support, training and change management activities. It also implies that ceasing these activities at the time of adoption may jeopardise the long-term acceptance of new technologies; instead support, training and change management should continue throughout users' deeper evaluation of the technology.

Another implication for IS practice is the importance of being first-to-market with some technological innovations. Nokia has captured the youth market for mobile phones and has set the standard for features and interfaces; the young people have mastered the Nokia handset and this sets their expectations for other handsets. Most of the young people were familiar with the Nokia interface for mobile phones: their understanding of the essential functions of a mobile phone are set and they have an accepted standard for the interface. 


\section{CONCLUSION}

Stages 1 and 2 of the research project have produced a robust model of young people's appropriation of mobile technologies. The model was developed in Stage 1 through benchmarking young people's current practices and examining their perceptions and use of mobile technologies (Carroll et al 2001; 2002). In Stage 2 , reported in this paper, we tested and refined the model by studying young people's responses to an unfamiliar technology. Further work in Stage 3 seeks to use this understanding of technology appropriation to envision young people's future needs and situations of use in order to design innovative technologies (see Howard et al. 2002).

There are a number of shortcomings of the research reported in this paper. Most important is the removal of cost as an influence on use. We were faced with a dilemma: young people are extremely cost-conscious but thorough exploration and use of a WAP phone is expensive and so may prove too costly for many young people. We chose to remove cost as a variable but acknowledge that this affected the young people's use patterns. As a consequence of providing a free handset and phone usage, there was a strong incentive at the initial encounter with the technology for the participants to move into the process of appropriation rather than into non-appropriation. In addition, having free use of a phone was acknowledged by most participants to have changed their behaviour. A particularly surprising outcome was that, despite having a free phone and free usage, many participants partially or wholly disappropriated the phones.

Secondly, the WAP phones were trialled only for a short period (one month) and had to be returned at the end of the research. We were unsure of what length of time would constitute medium and long-term use for mobile technologies and estimated that one month was sufficient to see Level 2 influences in operation. Analysis of the data suggests that one month was somewhat too brief to study Level 2 influences for a new technology and that the drift from Level 1 to Level 2 was only partially completed during this time.

Thirdly, knowing that the phones would be returned limited some participants' activities: few used the schedule or entered confidential information; one participant stated that "I would have gone more in-depth into the phone if I was actually keeping it."

Finally, a significant shortcoming of the research was the focus on individual not group appropriation. We have noted that social issues are critical to technology appropriation and that mobile technologies are social as well as personal technologies (Carroll et al. 2001). This research examined individual young people and their appropriation of mobile technologies. In future research, therefore, we plan to investigate the appropriation of mobile technologies over longer periods of time and by groups of young people.

\section{ACKNOWLEDGEMENTS}

This research was jointly funded by the University of Melbourne through a Department of Information Systems Early Career Research Grant and Novell through their Customers of the Future program.

\section{REFERENCES}

Bijker, W.E. and Law, J. (1992b). General introduction. In W.E. Bijker and J. Law (eds), Shaping technology/building society: studies in sociotechnical change. The MIT Press: Cambridge, MA.

Carroll, J., Howard, S., Vetere, F., Peck, J. and Murphy, J. (2001). Identity, power and fragmentation in cyberspace: technology appropriation by young people. In G. Finnie, D. Cecez-Kecmanovic and B. Lo (eds), Proceedings of the $12^{\text {th }}$ Australasian Conference on Information Systems (ACIS 2001). Vol. 1, 95-102.

Carroll, J., Howard, S., Vetere, F., Peck, J. and Murphy, J. (2002a). Just what do the youth of today want? Technology appropriation by young people. In R.H. Sprague (ed.) Proceedings of the 35th Hawaii International Conference on System Sciences (HICSS-35), January 2002, Maui, Hawaii, Institute of Electrical and Electronics Engineers, Inc. (IEEE). CD-ROM. 9 pages.

Carroll, J.M., Howard, S., Peck, J. and Murphy, J. (2002b). Young Australians and mobile technologies. What do young people want? How do they use mobile technologies? Journal of Information Technology Theory and Application (JITTA) (forthcoming).

Carroll, J.M. and Swatman, P. A. (2000). Structured-case: A Methodological Framework for Building Theory in Information Systems Research. European Journal of Information Systems, 9:4, 235-242.

Davis, F.D. (1989). Perceived usefulness, perceived ease of use, and user acceptance of information technology, MIS Quarterly, 13:3, 319-340.

Davis, F.D., Bagozzi, R. and Warshaw, P.R. (1989). User acceptance of computer technology, Management Science, 35:8, 982-1003.

Fichman, R.G. (1999). The illusory diffusion of innovation: an examination of assimilation gaps, Information Systems Research, 10:3, 255-275. 
Gooch, L. (2002). Upwardly mobile become soft targets, The Age, p.2 (April 10).

Howard, S., Carroll, J.M., Murphy, J., and Peck, J. (2002). Provoking innovation: acting-out in contextual scenarios. The British Computer Society Conference on HCI, London, September 2002 (forthcoming).

Karahanna, E., Straub, D.W. and Chervany, N.L. (1999). Information technology adoption across time: a cross-sectional comparison of pre-adoption and post-adoption beliefs, MIS Quarterly, 23:2, 183-213.

O'Malley, C.E, Draper, S.W. and Riley, M.S. (1984). Constructive Interaction: A Method for Studying Human-Computer-Human Interaction. Proceedings of IFIP INTERACT '84: Human-Computer Interaction, 269-274.

Rogers, E. (1995). Diffusion of innovations, $4^{\text {th }}$ ed., New York: Free Press.

Tyre, M.J. and Orlikowski, W.J. (1994). Windows of opportunity: temporal patterns in technology adaptation in organizations, Organization Science, 5:1, 98-118. 